Vol. 12 (2): 313-322 (2022)

\title{
ECOLOGICAL ECONOMIC MODEL OF FUNCTIONING OF NATURAL ECONOMIC COMPLEXES OF RIVER BASINS
}

\author{
A. T. Aimen ${ }^{1 *}$, D. O. Atasheva ${ }^{1}$, G. A. Sarbasova ${ }^{1}$, A. B. Moldasheva ${ }^{1}$, U. A. Orynbaeva ${ }^{1}$, \\ Z. Borkulakova ${ }^{1}$, D.M. Khazhgaliyeva ${ }^{1}$, M.A.Kaldygozova ${ }^{1}$ \\ ${ }^{1 *}$. Kh. DulatyTaraz Regional University, Taraz, Republic of Kazakhstan; \\ *Corresponding Author A. T. Aimen, email: aimenov_111@mail.ru; \\ Orcid: 0000-0001-9531-5432;
}

Received December 2021; Accepted January 2022; Published February 2022;

DOI: https://doi.org/10.31407/ijees12.201

\begin{abstract}
The object of the study is river basins, in which many irrigation complexes have been allocated for the development of agricultural production. Each irrigation complex, in turn, serves a set of farms - the main links of agricultural production. Naturally, the task of irrigation development in the river basin is considered in a certain sequence (river basin - irrigation system - irrigated economy); which allows to link sectoral planning with territorial planning and to take into account the interests of the development of agricultural sectors, economic zones and districts.
\end{abstract}

Keywords: rational use, water resources, transboundary rivers, water allocation, natural and economic complexes, river basins. 